\title{
PENGARUH KOMUNIKASI DAN KEPERCAYAAN TERHADAP EFEKTIVITAS TIM KELOMPOK KERJA GURU SEKOLAH DASAR KECAMATAN KOJA JAKARTA UTARA
}

\author{
Halimatusha'diah*
}

\begin{abstract}
The objective of this research is to obtain information concerning to the effect of communication and trust toward the effectiveness of teacher's teamwork. Data collection done toward 80 from 100 teachers of teacher's teamwork Dewi Sartika in the district Koja, North Jakarta. The methodologhy of this research used the survey method. Respondents were chosen by simple random sampling technique. The data were collected with questionnaire and analyzed with path analysis. Result of this analysis is concluded that (1) there is the postive direct effect of communication toward team effectiveness, (2) there is positive direct effect of trust toward team effectiveness, and (3) there is positive direct effect of communication toward trust.
\end{abstract}

Keyword: team effectiveness, communication, and trust.

\section{PENDAHULUAN}

Peningkatan kualitas pendidikan bukanlah suatu hal yang mudah untuk diimplementasikan. Semua pihak, baik pemerintah, tenaga pendidik dan kependidikan, maupun masyarakat, memiliki tanggungjawab bersama dalam memajukan pendidikan di Indonesia.

Sekolah merupakan salah satu organisasi pelayanan publik dalam bidang pendidikan yang dijadikan wadah bagi para guru dan murid untuk melakukan kegiatan belajar mengajar. Sekolah juga akan sangat erat kaitannya dengan masyarakat sebagai konsumen yang mengharapkan pelayanan dan mutu terbaik dari sekolah.

Salah satu hal yang dapat mendukung peningkatan mutu sekolah adalah kualitas guru sebagai tenaga pendidik, terutama di sekolah dasar, di mana proses pembelajaran dan pembentukan karakter murid masih lebih mudah untuk ditanamkan.

Berdasarkan Keputusan Mendikbud RI No. 0487 Tahun 1982 tentang Sekolah Dasar, dan Keputusan Dirjen Dikdasmen No. 079/C/Kep./I/1993, tentang Pedoman Pelaksanaan Sistem Pembinaan Profesional Guru melalui pembentukan gugus sekolah di sekolah dasar, maka salah satu wadah yang dapat digunakan untuk membina dan meningkatkan profesionalitas guru sekolah dasar di antaranya melalui kelompok kerja guru (KKG).

Adapun fungsi dari KKG sebagaimana yang tertulis dalam Buku Pedoman Pengelolaan Gugus Sekolah adalah (1) menyusun kegiatan KKG satu tahun dibimbing pengawas, tutor dan guru pemandu; (2) menampung dan memecahkan masalah yang dihadapi guru dalam kegiatan belajar-mengajar melalui pertemuan, diskusi, contoh mengajar, demonstrasi penggunaan dan pembuatan alat peraga. Sedangkan tujuan dari KKG itu sendiri adalah membantu meningkatkan kemampuan guru secara profesional dalam melaksanakan tugasnya yaitu keberhasilan kegiatan belajar-mengajar.

Namun kondisi yang terjadi saat ini, masih banyak KKG yang tidak berjalan dengan efektif. KKG yang seharusnya menjadi wadah untuk mengadakan pelatihan-

\footnotetext{
* Guru Honorer di Jakarta Utara
} 
pelatihan dalam membantu guru meningkatkan kompetensi dan mengatasi berbagai masalah yang dihadapi dalam proses belajar mengajar sampai saat ini masih belum berjalan dengan baik.

Data hasil survei dari Federasi Serikat Guru Indonesia (FGSI) pada Agustus sampai November 2012, mencatat bahwa sekitar 62\% dari 1.700 guru SD yang disurvei di 20 Kabupaten/Kota masih sedikit yang mendapatkan pelatihan-pelatihan yang layak untuk meningkatkan profesionalitas mereka, dan salah satu daerah tersebut adalah Jakarta. Kondisi tersebut dengan demikian menunjukkan bahwa salah satu wadah pembinaan profesional guru seperti KKG belum dapat berfungsi dengan baik.

Masalah yang terjadi yang dihadapi oleh para guru di setiap harinya tentu memiliki tingkat kesulitan yang berbeda-beda, sehingga butuh masukan, solusi, dan penyegaran bagi para guru untuk dapat meningkatkan kualitas mengajar mereka.

KKG sebagai sebuah tim dengan latar belakang para guru yang bervariasi, baik dari segi lingkungan sekolah, pengalaman, penguasaan materi, metode pengajaran, pengelolaan kelas, maupun dari segi jenjang pendidikan, seharusnya dapat menjadi wadah yang mumpuni untuk mengadakan pelatihan dan saling berbagi informasi dan ide-ide kepada sesama guru untuk memberikan solusi dan meningkatkan profesionalitas mereka.

Salah satu hal yang seharusnya diperhatikan oleh para guru adalah dengan membangun komunikasi yang efektif antar sesama anggota agar mereka dapat saling membantu, memotivasi, dan mengaktifkan KKG yang masih cenderung pasif.

Rendahnya komunikasi yang terjalin antar sesama anggota tim dapat menjadi salah satu faktor tidak efektifnya KKG saat ini, karena hal tersebut menjadikan koordinasi antar sesama anggota menjadi tidak efektif, sesama anggota juga tidak akan saling terbuka dalam mengungkapkan ide, masalah, solusi, dan informasi-informasi penting. Hal tersebut cenderung akan mengarahkan kepada hubungan yang tidak harmonis antara satu dengan yang lain karena tidak terbangunnya iklim kepercayaan yang baik antara satu dengan yang lain. Rendahnya iklim kepercayaan yang diciptakan dalam sebuah tim juga dapat menjadi salah satu penyebab rendahnya efektivitas tim. Karena setiap anggota tentu akan merasa sulit untuk bisa bekerjasama dengan baik dengan orang yang tidak dipercayai olehnya.

KKG sebagai sebuah tim dengan latar belakang para guru yang berbeda-beda, baik dari segi lingkungan sekolah, pengalaman, penguasaan materi, metode pengajaran, pengelolaan kelas, maupun dari segi jenjang pendidikan, seharusnya dapat menjadi wadah yang kaya akan informasi, ide-ide, solusi, dan berbagai bentuk pelatihan agar para guru mendapat penyegaran dalam mengajar siswa mereka.

Oleh karenanya, dengan masih rendahnya efektivitas tim KKG saat ini, menjadikan peneliti tertarik untuk meneliti lebih dalam lagi mengenai efektivitas tim KKG yang akan dilakukan di KKG Sekolah Dasar, Kecamatan Koja - Jakarta Utara.

\section{Efektivitas Tim}

Pada dasarnya tim-tim yang dibentuk dalam sebuah organisasi merupakan suatu bentuk upaya dan kesadaran bahwa hasil kerja sebuah tim akan memberikan kontribusi yang lebih besar untuk organisasi dari pada hasil kerja yang dicapai oleh perorangan atau individu. Oleh karenanya, efektivitas tim memiliki peranan penting dalam mencapai tujuan organisasi secara maksimal.

Efektivitas tim didefinisikan oleh Schermerhorn et al. (2011:162-163) sebagai berikut, "In OB (Organizational Behavior) we define an effective team as one that achieves high 
levels of task performance, member satisfaction, and team viability." Dalam perilaku organisasi, efektivitas tim didefinisikan sebagai sebuah tim yang mencapai tingkatan yang tinggi/hasil maksimal dalam kinerja, kepuasan personal, dan kelangsungan tim.

Hasil maksimal dalam kinerja menunjukkan adanya tanggungjawab tinggi yang dimiliki oleh anggota tim dalam melaksanakan dan menyelesaikan tugas sesuai dengan standar kualitas, kuantitas, dan batas waktu yang telah ditentukan dalam tim tersebut. Kepuasan anggota menunjukkan kepuasan mereka dengan tugas, pencapaian, dan hubungan interpersonal yang mereka dapatkan dalam tim. Dan kelangsungan tim yang berarti bahwa eksistensi tim dapat terjaga dengan baik karena para anggota di dalamnya merasa puas untuk terus bekerjasama dalam tim tersebut.

Sundstrom, DeMeuse, dan Futrell, sebagaimana dikutip oleh Daft (2012:523) mendefinisikan efektivitas tim sebagai berikut, "work team effectiveness is based on three outcomes - productive output, personal satisfaction, and the capacity to adapt and learn." Efektivitas tim adalah dilandaskan pada tiga hasil yang dicapai, yaitu hasil yang produktif, kepuasan personal atau pribadi, dan kemampuan untuk beradaptasi dan belajar.

Efektivitas tim selanjutnya didefinsikan oleh Nadler, Hackman, dan Lawler sebagaimana dikutip Bateman dan Snell (2002:447-448), "team effectiveness is defined by three criteria: First, the productive output of the team meets or exceeds the standards of quantity and quality; the team's output is acceptable to those customers, inside or outside the organizations, who recieve the teams's products or services....... Second, team members realize satisfaction of their personal needs...... Third, team members remain committed to work together again; that is, the group doesn't burn out and disintegrate after a grueling project......."

Pendapat tersebut menjelaskan bahwa efektivitas tim didefinisikan dengan tiga kriteria: Pertama, efektivitas tim ditunjukkan dengan adanya hasil produktif yang dicapai yang dapat memenuhi atau bahkan mampu melebihi standar kualitas dan kuantitas yang telah ditetapkan. Hasil yang dicapai tersebut juga dapat diterima oleh para konsumen, baik di luar maupun di dalam organisasi. Kedua, efektivitas tim ditunjukkan dengan terpenuhinya kebutuhan personal anggota tim, sehingga mereka mendapatkan kepuasan tersendiri dengan bekerja di dalam tim tersebut. Ketiga, efektivitas tim ditunjukkan dengan adanya komitmen dan keinginan anggota tim untuk bisa tetap bekerja bersama-sama lagi. Dengan demikian, hal ini menunjukkan bahwa kelangsungan tim tetap terjaga dengan baik dan tidak terpecah meskipun setelah menyelesaikan pekerjaan yang sulit.

Baker dan Gerlowski sebagaimana dikutip oleh Certo dan Certo (2012:458) berpendapat bahwa, "effective teams are those that come up with innovative ideas, accomplish their goals, and adapt to change when necessary." Pendapat ini menjelaskan bahwa tim-tim yang efektif adalah mereka yang dapat menemukan ide-ide inovatif, mencapai tujuantujuannya, dan mampu beradaptasi untuk dapat berubah ketika diperlukan.

Sebuah tim dengan anggota yang mampu melahirkan ide-ide inovatif akan sangat memberikan kontribusi besar terhadap hasil yang akan dicapai dalam tim. Ide-ide inovatif yang terus dimunculkan menunjukkan bahwa sebuah tim mampu berkembang, tidak pasif, dan tim tersebut adalah tim yang efektif. Anggota tim yang berhasil mencapai tujuannya dapat dikatakan sebagai tim yang efektif karena hal tersebut menunjukkan bahwa para anggota memiliki komitmen yang kuat, mampu bekerjasama dengan baik, dan lebih mementingkan kepentingan bersama daripada individu.

Kemampuan beradaptasi merupakan salah satu poin penting yang juga disebutkan oleh pendapat sebelumnya untuk menunjukkan efektivitas sebuah tim. Tidak jauh berbeda dengan penjelasan pada pendapat sebelumnya bahwa perubahan 
kondisi dalam tim, baik dari segi iklim kerja, hubungan interpersonal, dan perilaku anggota tim sangat mungkin terjadi secara tidak tentu. Ketika para anggota tim mampu mengantisipasi berbagai perubahan tersebut dengan kemampuan mereka untuk beradaptasi, maka hal tersebut menunjukkan bahwa tim tersebut adalah tim yang efektif.

Balzac (2011:88) berpendapat bahwa, "effecive teams are post-heroic. In other words, they help and support one another and are dedicated to accomplishing the goals of the company rather than being out solely for themselves. Tim-tim yang efektif adalah mereka yang lebih suka membantu dan mendukung satu sama lain dan yang didedikasikan untuk mencapai tujuan-tujuan perusahaan, dari pada bekerja secara individu untuk diri mereka sendiri. Pendapat di atas menjelaskan dua poin penting yang dapat digarisbawahi mengenai tim yang efektif, yaitu pertama, tim yang efektif ditunjukkan dengan adanya solidaritas antar sesama anggota di dalamnya, saling berbagi dan tidak bekerja secara individu. Kedua, para anggota tim bekerja untuk mencapai tujuan dan kepentingan bersama dan bukan kepentingan individu.

Berdasarkan deskripsi dari beberapa konsep efektivitas tim di atas, maka dapat disintesiskan bahwa efektivitas tim adalah pencapaian hasil maksimal para anggota tim yang dapat dinilai dengan indikator penyelesaian tugas dengan baik, kepuasan personal yang terpenuhi, kelangsungan tim yang terjaga, pencapaian hasil yang produktif, tercapainya tujuan bersama, ide-ide inovatif, dan adaptasi yang efektif.

\section{Komunikasi}

Komunikasi merupakan elemen yang sangat penting dalam melakukan interaksi sosial terutama dalam sebuah kelompok. Goetsch dan Davis (2000:307) berpendapat bahwa, "communication is the transfer of a message (information, idea, emotion, intent, feeling, or something else) that is both received and understood." Komunikasi didefinisikan oleh pendapat ini sebagai penyampaian pesan yang dapat berupa informasi, ide, emosi, tujuan, perasaan, dan lain sebagainya, yang dapat diterima dan dimengerti oleh orang lain. Pendapat ini menunjukkan bahwa ketika komunikasi terjadi, maka di dalamnya terdapat sebuah pesan yang terkandung untuk disampaikan kepada orang lain.

O'Reilly dan Pondy sebagaimana dikutip oleh Waddell et al. (2007:382) berpendapat bahwa, "communication is the sharing of information between two or more people or groups to reach a common understanding." Dalam pendapat ini, komunikasi diartikan dengan berbagi informasi antara dua orang atau lebih atau dalam kelompok-kelompok untuk sampai kepada suatu pemahaman yang sama. Lebih lanjut hal ini dijelaskan oleh Waddell sebagai berikut, "first and foremost, communication, no matter how it is carried out, is a human endeavour and involves individuals and groups. Second, communication does not take place unless a common understanding is reached.

Pendapat ini lebih lanjut menjelaskan bahwa terdapat dua hal penting dari pendefinisian komunikasi. Pertama adalah bahwa komunikasi dianggap sebagai sebuah upaya seseorang (untuk berbagi informasi yang dimiliki) tanpa mempermasalahkan bagaimana cara yang dilakukan untuk menyampaikan informasi tersebut, dan hal ini melibatkan individu ataupun kelompok. Kedua, komunikasi tersebut dianggap tidak terjadi ketika tidak ada pemahaman yang sama yang dicapai dari informasi yang telah disampaikan.

Selanjutnya yaitu pendapat dari Daft (2012:495) bahwa, "communication is the process by which information is exchanged and understood by two or more people, usually with the intent to motivate or influence behavior." Menurut Daft komunikasi merupakan proses 
pertukaran dan pemahaman informasi yang dilakukan oleh dua orang atau lebih, dan biasanya proses tersebut juga memiliki maksud untuk memotivasi atau memengaruhi perilaku orang lain. Hal yang dapat digarisbawahi dari pendapat ini adalah bahwa seseorang melakukan komunikasi tidak hanya sekedar untuk menyampaikan pesan dan mencapai kesepahaman, tetapi juga karena memiliki suatu tujuan tertentu, seperti halnya untuk memotivasi dan memengaruhi perilaku orang lain.

Pendapat lainnya tentang komunikasi yaitu disampaikan oleh Shani et al. (2009:175), "communication is the transfer of information from one person to another. As such, the communication episode entails the transfer of information from one person (the sender) to another (the receiver)by some chosen method (the cannel)." Komunikasi menurut pendapat ini diartikan sebagai penyampaian informasi dari seseorang kepada orang lain. Penyampaian informasi dalam komunikasi yang dilakukan oleh pengirim kepada penerima pesan membutuhkan saluran atau media sebagai cara untuk menyampaikan pesan tersebut.

Dengan demikian, dari berbagai konsep komunikasi komunikasi, maka dapat disintesiskan bahwa komunikasi adalah proses penyampaian pesan yang dilakukan oleh pengirim kepada penerima pesan dengan indikator adanya pesan, kesepahaman, adanya tujuan, dan penggunaan media.

\section{Kepercayaan}

Kepercayaan merupakan salah satu komponen penting dalam sebuah organisasi dan tim. Tujuan organisasi dan tim akan lebih mudah tercapai ketika kepercayaan dapat dibangun dengan baik antara sesama anggota di dalamnya.

Kepercayaan didefinisikan oleh Mayer, Davis, dan Schoorman sebagaimana dikutip oleh Colquitt, Lepine, dan Wesson (2011:219) sebagai berikut, "trust is defined as the willingness to be vulnerable to a trustee based on positive expectations about the trustee's actions and intentions." Pendapat ini menjelaskan bahwa kepercayaan berarti adanya kerelaan atau kesediaan seseorang untuk berada pada kondisi rawan atau beresiko karena adanya harapan positif terhadap tindakan dan maksud orang lain (yang dipercaya).

Janasz, Dowd, dan Schneider (2009:33) berpendapat bahwa, "trust is a multifaced concept that captures one's faith or belief in the integrity or reliability of another person or thing." Pendapat ini menjelaskan kepercayaan sebagai keyakinan seseorang terhadap orang lain yang muncul berdasarkan integritas atau reliabilitas yang dimiliki orang tersebut. Integritas atau reliabilitas inilah yang menjadi tolak ukur layak atau tidaknya seseorang untuk dipercaya oleh orang lain.

Selanjutnya yaitu pendapat dari Newstrom (2011:277) yang menjelaskan kepercayaan sebagai berikut, "the capacity to voluntarily depend on each other's word and actions." Kepercayaan merupakan kapasitas untuk dapat bergantung kepada ucapan dan tindakan satu sama lain. Pendapat ini menunjukkan bahwa kepercayaan muncul karena adanya kapasitas atau kemampuan yang dimiliki seseorang sehingga dianggap layak untuk dipercaya.

Colquitt, LePine, dan Wesson (2011:223-224) berpendapat bahwa layak atau tidaknya seseorang untuk dipercaya dapat dilihat berdasarkan tiga dimensi berikut ini, "the first dimension of trustworthiness is ability, ..... . The second dimension of trustworthiness is benevolence, ..... . The third dimension of trustworthiness is integrity, ...... . Tiga dimensi kelayakan seseorang untuk dipercaya menurut pendapat ini adalah dilihat dari kemampuan, kebaikan, dan integritas. Ketiga dimensi tersebut digolongkan oleh para ahli ini ke dalam bentuk kepercayaan berdasarkan kognisi atau cognition-based trust. 
Whetten dan Cameron (2007:455) berpendapat bahwa, "foster trust ......... by providing support and creating confidence, primarily by being consistent, honest, open, and fair." Pendapat ini menjelaskan bahwa kepercayaan seseorang dapat terjaga apabila adanya dukungan dan keyakinan, terutama dengan menjadi konsisten, jujur, terbuka, dan adil.

Terkahir adalah pendapat dari Schindler dan Thomas sebagaimana dikutip oleh Robbins dan Coulter (2012:501) berpendapat bahwa kepercayaan terbentuk berdasarkan lima dimensi berikut ini, "research has identified five dimensions that make up the concept of trust: (1) integrity, (2) competency, (3) consistency, (4) loyalty, (5) openness." Pendapat ini menjelaskan bahwa terdapat lima dimensi yang mendasari konsep kepercayaan, yaitu: (1) integritas, (2) kompetensi (3) konsistensi, (4) kesetiaan, (5) keterbukaan.

Dari berbagai konsep mengenai kepercayaan seperti tersebut di atas, maka dapat disintesiskan bahwa kepercayaan adalah harapan positif seseorang kepada orang lain yang melibatkan sebuah resiko di dalamnya, yang dapat diukur dengan sifat dapat dipercaya, kemampuan menyelesaikan tugas, kebajikan, konsistensi, kesetiaan, keterbukaan, dan sikap yang adil.

\section{METODE}

Metode yang digunakan dalam penelitian ini adalah metode survey dengan menggunakan pendekatan kuantitatif dan menjelaskan hubungan kausal dengan analisis jalur (path analysis). Hasil uji coba instrumen variabel efektivitas tim dari 34 butir yang telah diujicobakan, terdapat 1 butir yang tidak valid dengan koefisien reliabilitas instrument sebesar 0,973. Hasil uji coba intrumen pada variabel komunikasi diperoleh 5 butir yang tidak valid dari jumlah butir yang telah diujicobakan sebanyak 30, dengan koefisien reliabilitas instrumen sebesar 0,945. Hasil uji coba intrumen untuk variabel kepercayaan dari 37 butir yang telah diujicobakan, terdapat 4 butir yang tidak valid dengan koefisien reliabilitas instrumen sebesar 0,959. Adapun analisis data dilakukan dengan statistika deskriptif dan inferensial.

\section{HASIL DAN PEMBAHASAN}

\section{Komunikasi terhadap Efektivitas Tim}

Dari hasil perhitungan analisis jalur, pengaruh langsung komunikasi terhadap efektivitas tim, nilai koefisien jalur $\rho_{31}$ diperoleh sebesar 0,474 dengan $t_{\text {hitung }}$ sebesar 4,74 $\left(\mathrm{t}\right.$ hitung $\left.4,74>\mathrm{t}_{\text {tabel }} 1,67\right)$ dan koefisien korelasi $r_{13}$ sebesar 0,519 . Hal ini berarti bahwa komunikasi berpengaruh langsung positif terhadap efektivitas tim. Hal ini sesuai dengan teori dari Ivancevich, Konopaske, dan Matteson (2008:278) berpendapat bahwa, "one of the more significant effects creating teams has on an organization's management is an increased need for information. Team members need information in order to accomplish their objectives. Salah satu pengaruh yang sangat signifikan membentuk tim adalah dengan meningkatkan informasi-informasi yang dibutuhkan. Anggota tim akan sangat membutuhkan informasi yang memadai untuk menyempurnakan tujuan bersama yang ingin dicapai..

Selanjutnya yaitu teori dari McShane dan Von Glinow (2010:239) berpendapat bahwa, "communication systems can influence team effectiveness, particularly in virtual teams, which are highly dependent on information technologies to coordinate work." Sistem komunikasi dapat mempengaruhi efektivitas tim, terutama dalam sebuah tim virtual, yang sangat memiliki ketergantungan terhadap teknologi informasi untuk mengkoordinasikan pekerjaan. Terakhir adalah teori dari Schremerhorn et. al (2011:168) 
yang menjelaskan bahwa dalam kinerja tim, komunikasi merupakan bagian dari proses di dalamnya yang mampu memberikan pengaruh terhadap efektivitas tim sebagai sebuah bentuk output (hasil) dari kinerja tim.

\section{Kepercayaan terhadap Efektivitas Tim}

Dari hasil perhitungan analisis jalur, pengaruh langsung kepercayaan terhadap efektivitas tim, diperoleh nilai koefisien jalur $\rho_{32}$ sebesar 0,201 dengan $t_{\text {hitung }}$ sebesar 2,01 $\left(\mathrm{t}\right.$ hitung 2,01 $>\mathrm{t}_{\text {tabel }}$ 1,67) dan koefisien korelasi $r_{23}$ sebesar 0,292. Hal ini berarti bahwa kepercayaan berpengaruh langsung positif terhadap efektivitas tim. Hal ini sesuai dengan teori dari Newstrom (2011:341), "the presence of trust is essential to most effective team." Adanya kepercayaan merupakan hal yang sangat penting untuk tim yang efektif.

Teori selanjutnya yaitu dari Robbins dan Judge (2011:354) yang menjelaskan bahwa, "members of effective team trust each other. ...... Interpersonal trust among team members facilitates cooperation, reduces the need to monitor each others' behavior, and bonds members around the belief that others on the team won't take advantage of team." Anggota dalam sebuah tim yang efektif itu saling mempercayai satu sama lain. Dengan adanya kepercayaan antar sesama anggota tim akan memudahkan terbangunnya kerjasama yang baik, mengurangi adanya rasa saling curiga, dan meyakini bahwa sesama anggota dalam tim tersebut tidak akan saling mengambil keuntungan.

Gibson et al. (2006:253-254), "on team level, there must exist a high level of trust among members." Dalam tim tingkat kepercayaan yang tinggi harus terjadi antara satu dengan anggota lainnya. Pendapat lainnya yaitu dikemukakan oleh Newstrom (2011:341), "the presence of trust is essential to most effective team." Adanya kepercayaan merupakan hal yang sangat penting untuk tim yang efektif. Terkahir adalah pendapat dari Cassidy dan Kreitner (2010:44) yang berpendapat bahwa, "trust is a key ingredient for any successful team." Kepercayaan merupakan sebuah komposisi penting untuk kesuksesan tim. 


\section{Komunikasi terhadap kepercayaan}

Dari hasil perhitungan analisis jalur, pengaruh langsung komunikasi terhadap kepercayaan, diperoleh nilai koefisien jalur $\rho_{21}$ sebesar 0,321 , dengan $t_{\text {hitung sebesar 2,97 }}$ ( $\left.\mathrm{t}_{\text {hitung }} 2,97>\mathrm{t}_{\text {tabel }} 1,67\right)$ dan koefisien korelasi $r_{12}$ sebesar 0,321 . Hal ini berarti bahwa komunikasi berpengaruh langsung positif terhadap kepercayaan. Hal tersebut sesuai dengan teori yang dikemukakan oleh Tobin dan Pettingell (2008-58) sebagai berikut, "being clear and direct in communications, especially about real or potential problems, helps to build trust." Teori di atas menerangkan bahwa komunikasi yang jelas dan secara langsung, terutama ketika terjadi permasalahan yang penting, akan membantu dalam membangun kepercayaan.

O'Brien (2001:51) dalam teorinya berpendapat bahwa, "developing trust in an organization depends on a number of interrelated factors: communication is the first step to creating trust.......". Membangun kepercayaan dalam organisasi bergantung pada beberapa faktor yang salah satunya yaitu komunikasi sebagai langkah utama untuk membentuk kepercayaan.

Dan terakhir yaitu teori dari Levi (2007:96), "when team members take a chance and communicate, they can receive supportive responses. These responses encourage trust and openness, which increase their willingness to communicate again, further increasing trust and creating a supportive climate. Communication that receives deffensive responses, such as negative evaluations and sacrastic comments, can lead to less trust and greater self-protection. A defensive climate results, which in turn leads to conflict or withdrawal." Pendapat ini menjelaskan bahwa ketika anggota tim mengambil waktu untuk berkomunikasi, mereka bisa mendapatkan respon suportif dan respon defensif. Respon-respon suportif atau mendukung akan mendorong tingkat kepercayaan dan keterbukaan yang kemudian akan meningkatkan keinginan para anggota tim untuk melakukan komunikasi kembali. Sedangkan komunikasi yang menghasilkan respon defensif cenderung akan mengarahkan kepada penurunan tingkat kepercayaan dan dapat memicu konflik.

\section{PENUTUP}

\section{Kesimpulan}

Berdasarkan hasil penelitian yang dilakukan dengan semua persyaratan analisis data yang meliputi uji linieritas dan keberartian regresi yang telah dipenuhi, maka disimpulkan bahwa:

1. Terdapat pengaruh langsung positif komunikasi terhadap efektivitas tim. Artinya ketika komunikasi semakin baik, maka efektivitas tim juga akan meningkat,

2. Terdapat pengaruh langsung positif kepercayaan terhadap efektivitas tim, artinya jika kepercayaan semakin tinggi, maka tingkat efektivitas juga akan semakin tinggi,

3. Terdapat pengaruh langsung positif komunikasi terhadap kepercayaan. Hal ini menunjukkan bahwa jika tingkat komunikasi yang dilakukan semakin tinggi, maka tingkat kepercayaan juga akan semakin tinggi. 


\section{Saran}

Adapun hasil penelitian ini pada akhirnya dapat digunakan bagi para guru untuk meningkatkan efektivitas tim KKG Sekolah Dasar di wilayah kecamatan Koja, Jakarta Utara, dengan memperhatikan beberapa faktor sebagai berikut:

1. Faktor komunikasi antar sesama anggota KKG yang diharapkan mampu ditingkatkan menjadi lebih baik lagi agar terciptanya koordinasi, pertukaran informasi, dan hubungan interpersonal yang baik sehingga KKG akan berjalan lebih efektif.

2. Faktor kepercayaan antar sesama anggota KKG yang sudah seharusnya ditingkatkan dalam KKG, karena dengan iklim kepercayaan yang semakin baik, akan memudahkan para anggota untuk saling bekerjasama antara satu dengan yang lain, sehingga efektivitas KKG dapat terpelihara dengan baik.

3. Selain adanya faktor komunikasi dan kepercayaan, efektivitas KKG sebenarnya dapat ditingkatkan dari kesadaran dan peran serta para anggotanya untuk aktif dalam membangun KKG agar menjadi lebih efektif. 


\section{DAFTAR RUJUKAN}

Balzac, Stephen R. Organizational Development. New York: McGraw-Hill, 2011.

Bartol, Kathryn, et al. Management: A Pasific Rim Focus. New South Wales: McGraw-Hill Australia, 2003.

Bateman, Thomas S. dan Scott A. Snell. Management: Competing in the New Era. New York: McGraw-Hill, 2002.

Cassidy, Carlene dan Robert Kreitner, Supervision: Setting People Up For Success. Mason: South-Western Cengage Learning, 2010.

Colquitt, Jason A., Jeffery A. LePine, dan Michael J. Wesson. Organizational Behavior: Improving Performance and Commitment in the Workplace, Second Edition. New York: McGraw-Hill, 2011.

Daft, Richard L. New Era of Management, Tenth Edition. China: Sout-Western Cengage Learning, 2012.

Goetsch, David L. dan Stanley B. Davis. Quality Management: Introduction to Total Quality Management for Production, Processing, and Services (New Jersey: Prentice-Hall, Inc., 2000.

Gibson et al., Organizations: Behavior, Structure, Processes. New York: McGraw-Hill, 2006.

http://sdnpurwaraja4.do.am/news/kegiatan_kelompok_kerja_guru_kkg_solusi_mini mnnya_pelatihan_guru_tingkat_sekolah_dasar/2012-12-06-16 (diakses pada $28 \mathrm{Mei}$ 2013).

Ivancevich, Konopaske, dan Matteson, Organizational Behavior and Management (New York: McGraw-Hill, 2008), h. 278.

Janasz, Suzanne C. De, Karen O. Dowd, dan Beth Z. Schneider. Interpersonal Skills in Organizations, Third Edition. New York: McGraw-Hill, 2009.

McShane, Steven L. dan Mary Ann Von Glinow, Organizational Behavior. New York: McGraw-Hill Irwin, 2010.

Newstrom, John W. Organizational Behavior: Human Behavior at Work, Thirteenth Edition. New York: McGraw-Hill, 2011.

Levi, Daniel, Group Dynamics for Teams. California: Sage Publications, 2007.

O'Brien, Rita Cruise, Trust: Releasing the Energy to Socceed. England: John Wiley \& Sons Ltd, 2001.

Robbins, Stephen P. dan Mary Coulter. Management, Eleventh Edition. England: Pearson Education, 2012. 
Schermerhorn, John R., et al. Organizational Behavior, Eleventh Edition. Asia: John Wiley \& Sons, 2011.

Shani, A. B. (Rami), et al. Behavior in Organizations: An Experential Approach. New York: McGraw-Hill, 2009.

Waddell, Dianne, et al. Contemporary Management. New South Wales: McGraw-Hill Australia Pty Limited, 2007.

Whetten, David A. dan Kim S. Cameron. Developing Management, Seventh Edition. New Jersey: Pearson Prentice Hall, 2007. 